$\begin{array}{lll}\text { Article History: } & \text { Submitted } & : 09 / 06 / 2021 \\ \text { ISSN: 2356-4547 (Print), 2721-0006 (Online) } & \text { Reviewed } & : 16 / 06 / 2021 \\ \text { Vol. 8, No. 1, Oktober 2021, (104-130), https://s.id/Man_Raf } & \text { Accepted } & : 05 / 09 / 2021 \\ \text { Published By: Sekolah Tinggi Teologi Arastamar Bengkulu } & \text { Published } & : 31 / 10 / 2021\end{array}$

\title{
KAJIAN BIBLIKA KEBEBASAN FINANSIAL ALKITABIAH
}

\author{
Jhon Leonardo Presley Purba ${ }^{1}$ ), Priyantoro Widodo ${ }^{2}$ \\ Sekolah Tinggi Teologi Baptis Indonesia ${ }^{12}$ \\ *)Email Correspondence:jhonpresley@stbi.ac.id
}

\begin{abstract}
Finance is an important aspect in human life, so having financial freedom is the hope of many people. But poor financial management often makes a person depressed and frustrated. For Christians, the topic of discussion about money and its management is also often considered taboo and has worldly connotations. But in fact, the Bible has a lot to say about money and the principles of its management. The purpose of this study is to build a biblical study of financial freedom by explaining biblical principles on financial management to gain financial freedom. This research is presented in a qualitative-descriptive form through a topical presentation on finance to conduct a study and theological construction of Biblical financial freedom. The data collection and analysis model used is a literature study. Biblical financial freedom is a construction of financial management based on biblical principles. The results of this study a person can have the right heart and morals in managing finances wisely and well, refrain from falling into debt and credit bonds, use money to help others in need, dedicate all money and wealth to the glory of God with good management. , true, obedient and faithful to tithe.

Keywords: Biblical, Management, Finance, Tithing, Debt.
\end{abstract}

Abstraksi: Keuangan merupakan aspek penting dalam kehidupan manusia, sehingga memiliki kebebasan finansial merupakan harapan banyak orang. Tetapi pengelolaan keuangan yang tidak baik sering kali membuat seseorang menjadi depresi dan frustrasi. Bagi orang Kristen, topik pembahasan tentang uang dan pengelolaanya juga sering dianggap tabu dan dikonotasikan duniawi. Namun faktanya Alkitab banyak berbicara tentang uang dan prinsip-prinsip pengelolaanya. Tujuan penelitian ini adalah untuk membangun suatu kajian biblika kebebasan keuangan dengan memaparkan prinsip-prinsip Alkitab tentang pengelolaan keuangan untuk mendapatkan kebebasan finansial. Penelitian ini disajikan dalam bentuk kualitatifdeskriptif melalui pemaparan topikal tentang keuangan untuk melakukan kajian dan konstruksi teologis kebebasan finansial Alkitabiah. Model pengumpulan dan analisis data yang digunakan adalah studi pustaka. Kebebasan finansial Alkitabiah merupakan suatu konstruksi pengelolaan keuangan berdasarkan prinsip-prinsip Alkitab. Hasil penelitian ini seseorang dapat memiliki hati dan moral yang benar dalam mengelola keuangan dengan bijak dan baik, menahan diri untuk tidak terjerumus dalam ikatan hutang piutang, menggunakan uang untuk membantu orang lain yang membutuhkan, mempersembahkan seluruh uang dan kekayaan bagi kemuliaan Tuhan dengan pengelolaan yang baik, benar, taat dan setia memberi persepuluhan.

Kata Kunci : Biblika, Managemen, Keuangan, Persepuluhan, Hutang

\section{PENDAHULUAN}

Keuangan merupakan salah satu aspek yang tidak terpisahkan dari

kehidupan manusia di dunia ini, termasuk orang Kristen. Pada umumnya, 
pembahasan tentang keuangan menjadi hal yang tabu dan mudah disalahpahami bagi orang Kristen, karena dikonotasikan tidak rohani atau identikan dengan kehidupan duniawi. Namun faktanya, banyak orang dewasa maupun anak-anak muda Kristen yang mengalami stress dan kecemasan sebagai akibat dari ketidakstabilan finansial. ${ }^{1}$ Menurut Otoritas Jasa Keuangan (OJK), setiap orang perlu memiliki perencanaan keuangan pribadi maupun keluarga yang baik. Perencanaan keuangan adalah suatu skill mendasar untuk merencanakan dan mengatur keuangan agar pengelolaannya menjadi jelas dan terarah. Perencanaan keuangan untuk kebutuhan hidup dapat diklasifikasikan menjadi kebutuhan jangka pendek, jangka menengah dan jangka panjang. Perencanaan keuangan yang baik akan berimplikasi terhadap mudahnya melakukan pengendalian terhadap pengeluaran maupun alokasi dana yang telah dianggarkan. ${ }^{2}$ Orang Kristen perlu memahami prinsip ini, agar dapat memiliki perencanaan keuangan yang baik dengan tujuan yang benar sesuai dengan Firman Tuhan.

Orang Kristen ketika memikirkan uang pada umumnya berpikir sebagai hal-hal yang bersifat duniawi. Seharusnya, orang Kristen ketika memikirkan keuangan juga memikirkan tentang hal-hal rohani. Alkitab banyak berbicara dan mengajarkan tentang uang. ${ }^{3}$ Perry Stone menuliskan bahwa Alkitab yang terdiri dari 66 kitab (Perjanjian Lama dan Perjanjian Baru), berbicara banyak tentang uang dari pada subjek khusus yang lain. Bahkan 16 dari 40 perumpamaan Tuhan

\footnotetext{
1 Our Daily Bread, EP. 30: Money Mistakes and How to Cope, 2021, https://www.youtube.com/watch?v=luvFrskRFDg.

2 Otoritas Jasa Keuangan, Perencanaan Keuangan Keluarga, Perencanaan Keuangan Keluarga Dan Dampaknya Terhadap Peningkatan Kesejahteraan Masyarakat, 2017, x.

3 In Touch Ministries, God and Our Money - Dr. Charles Stanley, 2019, https://www.youtube.com/watch?v=HC-zhWIIC5w.
} 
Yesus saat mengajar berhubungan atau menyebutkan tentang uang. ${ }^{4}$ Subjek pengajaran tentang keuangan merupakan hal yang prinsip dan signifikan dalam Firman Tuhan. Hal ini terlihat dari fakta dalam Alkitab bahwa Tuhan memikirkan, berkata dan berjanji perihal keuangan bagi orang percaya.

Oleh sebab itu, dalam iman, hikmat dan ketaatan tidak salah mengharapkan kemurahan hati dan penyediaan Tuhan akan kebutuhan keuangan. ${ }^{5}$ Selain itu, orang Kristen juga membutuhkan prinsip-prinsip Alkitabiah untuk mengelola keuangan agar dapat mengantisipasi kesalahan pengelolaan keuangan yang dapat berakibat buruk bagi keadaan dan kebutuhan hidup, baik secara fisik, psikis maupun spritual. ${ }^{6}$ Jika pengelolaan keuangan dilakukan dengan benar, seberapa pun jumlahnya, maka akan membuat seseorang memiliki kestabilan finansial atau kebebasan finansial. Berdasarkan pemikiran di atas, artikel ini dimaksudkan untuk membangun suatu kajian biblika tentang kebebasan finansial Alkitabiah (Biblical financial freedom) yang memaparkan prinsip-prinsip Alkitabiah pengelolaan keuangan.

\section{METODE}

Penelitian ini disajikan dalam bentuk kualitatif-deskriptif ${ }^{7}$ melalui pemaparan topikal tentang keuangan untuk melakukan kajian dan konstruksi teologis kebebasan finansial Alkitabiah. Model pengumpulan dan analisis data

\footnotetext{
4 Perry Stone, A Study on Ancient Bible Currency (Perry Stone Ministry, 2018), https://www.youtube.com/watch?v=s5beE_TjwiA\&t=3s. zhWIIC5w.

${ }^{5}$ Ministries, God and Our Money - Dr. Charles Stanley, https://www.youtube.com/watch?v=HC-

6 John MacArthur, "Overcoming Financial Worry, Part 1," dalam Grace To You, 2021, https://www.gty.org/library/sermons-library/2248/overcoming-financial-worry-part-1.

7 Sonny Eli Zaluchu, "Strategi Penelitian Kualitatif dan Kuantitatif Di Dalam Penelitian Agama," Evangelikal: Jurnal Teologi Injili dan Pembinaan Warga Jemaat 4, no. 1 (2020): 28-38, https://doi.org/10.46445/ejti.v4i1.167.
} 
yang digunakan adalah studi pustaka yang berhubungan dengan kajian keuangan dalam Alkitab. Teori dan informasi dikumpulkan sebanyak mungkin dari bahan kepustakaan menyangkut topik penelitian melalui sumber-sumber yang relevan dan dapat dipertanggung jawabkan validitas dan keabsahannya seperti buku, jurnal, film dokumenter, laporan penelitian, eksiklopedia dan bahan-bahan kredibel lainnya berbasis online. ${ }^{8}$ Tahapan yang dilakukan untuk membangun konstruksi teologis kebebasan finansial Alkitabiah. Pertama, memaparkan konsep uang dalam Alkitab. Kedua, menguraikan dasar teori pentingnya memiliki kebebasan finansial. Ketiga, menguraikan prinsip-prinsip Alkitabiah untuk memperoleh kebebasan finansial Alkitabiah. Keempat, menyajikan kesimpulan paper.

\section{HASIL}

Kebebasan finansial Alkitabiah merupakan suatu konstruksi pengelolaan keuangan berdasarkan prinsip-prinsip Alkitabiah, agar seseorang dapat memiliki dan melakukan pengelolaan keuangannya dengan bebas dan mandiri berdasarkan prinsip-prinsip Alkitab. Sebagaimana yang diajarkan Tuhan Yesus Kristus, orang Kristen hendaknya memiliki hati dan moral yang benar, agar dapat mengelola keuangan dengan bijak dan baik. Caranya adalah dengan menahan diri untuk tidak terjerumus ke dalam ikatan hutang piutang, menggunakan sumber daya keuangan untuk membantu orang lain yang membutuhkan, mempersembahkan seluruh uang dan kekayaan bagi kemuliaan Tuhan dengan bukti ketaatan dan kesetiaan memberi persepuluhan. Penelitian menghasilkan konsep tentang implikasi praktis

8 Sonny Eli Zaluchu, "Metode Penelitian di dalam Manuskrip Jurnal IImiah Keagamaan," Jurnal Teologi Berita Hidup 3, no. 2 (2021), https://doi.org/10.38189/jtbh.v3i2.93. 
pengelolaan keuangan Alkitabiah, tujuan uang dan pengelolaannya dari prespektif Alkitabiah, hutang piutang dalam sistem pengelolaan keuangan Alkitabiah, moralitas dalam pengelolaan keuangan Alkitabiah, prinsip dasar kebebasan finansial Alkitabiah, dasar teori kebebasan finansial, konsep uang dalam perjanjian baru, konsep uang dalam perjanjian lama dan terminologi dan konsep uang dalam Alkitab.

\section{PEMBAHASAN}

Uang dalam terminologi modern adalah alat pembayaran dan alat penukar yang sah yang dikeluarkan oleh pemerintah. ${ }^{9}$ Uang menjadi alat tukar yang sah dalam sistem pembayaran terbentuk di abad pertengahan. Etimologi uang berasal dari kata Prancis kuno "moneie" atau "moonay" dan "mone". Kata "moneie" berakar dari kata Latin "moneta" artinya percetakan uang logam, berasal dari konsep moneta yaitu suatu gelar kultus dewi Juno di Roma tempat uang dicetak menjadi koin, dari sini kemudian berkembang tempat percetakan uang koin dari logam. ${ }^{10}$ Setelah ada uang hadir sistem managemen keuangan yang disebut finance, yang berasal dari bahasa Latin abad pertengahan financia artinya uang atau pembayaran untuk pajak atas daerah yang diduduki. ${ }^{11}$

Alkitab Perjanian Lama dan Perjanjian Baru menunjukkan bahwa uang telah digunakan sebagai alat pembayaran. Dalam terminologi Alkitab kata uang berasal dari kata Yunani $\alpha \rho \gamma \psi \rho\llcorner o v$ (argyrion) yang berarti "silver coin" (koin perak). Berasal dari kata $\alpha \rho \gamma \psi \rho \circ \sigma$ (argyros) yang berarti "logam yang baik."

${ }^{9}$ Ratu Aprilia Fajri, Em Zul \& Senja, Kamus Lengkap Bahasa Indonesia (Difa Publisher, 2010), 841.

${ }^{10}$ Robert K Barnhart, Dictionary of Etymology (New York: Wilson Company, 1995), 485.

11 Barnhart, 281. 
Bahan dasar logam perak ini diimpor dari daerah Arab dan Mesir, yang kemudian dibentuk menjadi plat perak (Lih. Kej. 24: 53, Kis. 17: 29, 19: 24, 2Tim. 2: 20) dan digunakan sebagai alat pembayaran (Kej. 23: 9, Kis. 7: 16, 19: 19). ${ }^{12}$

\section{Konsep Uang Dalam Perjanjian Lama}

Kata Ibrani כֶָָּ (keceph; keh'-sef) dalam Perjanjian Lama berarti silver atau perak, kata ini kemudian diartikan sebagai uang. Teks-teks Perjanjian Lama dan penemuan arkeologi menunjukkan bahwa perak telah diproduksi sejak tahun 4000 SM, kemudinan mulai tahun 3000 SM menjadi mata uang utama hingga penemuan mata uang pada abad ke $7 \mathrm{SM}^{13}$ Perak bukanlah satu-satunya alat pembayaran, namun perak merupakan alat pembayaran yang dominan dalam perdagangan. Itulah sebabnya kata Ibrani untuk "perak" כסף (kesef), juga menjadi istilah Ibrani modern untuk uang dan kata Ibrani untuk "berat" שקל (syikal) menjadi istilah Ibrani modern untuk koin standar. ${ }^{14}$ Syikal adalah standar satuan untuk berat logam perak yang digunakan pada masa Perjanjian Lama. ${ }^{15}$ Syikal berasal dari kata Ibrani sheqel (Gk. Siklos) artinya "berat" 16, suatu ukuran berat pada zaman kuno yang terbuat dari perak senilai satu tetradrachma (dalam Perjanjian Baru drachma adalah satuan uang berbentuk sebuah koin perak) ${ }^{17}$, yang menjadi satuan uang Yahudi saat itu. Setara dengan upah 4 hari kerja yaitu 4 dinar. Pada saat ini syikal menjadi nama satuan uang di Israel modern.

\footnotetext{
12 Xavier Leon-Dufour, Dictionary of the New Testament (New York: Harper and Row Publishers, 1983), 293-94.

13 James Strong, A Consise Dictionary Of The Words In The Hebrew Bible, 1890, 674.

14 Tzilla Eshel, "How Silver Was Used for Payment," thetorah.com, 2018.

15 Leon-Dufour, Dictionary of the New Testament, 293.

16 Leon-Dufour, 370.

17 Mark Longman, Tremper \& Enns, Peter \& Strauss, The Baker Illustrated Bible Dictionary (Grand Rapids Michigan, USA: Baker Publishing, 2013), 1026.
} 


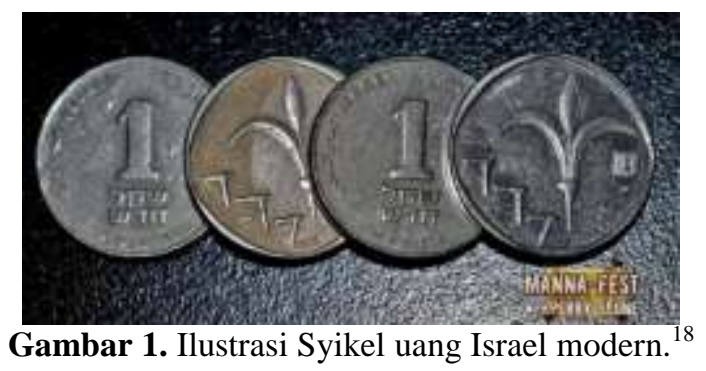

Uang pertama kali disebutkan di Alkitab saat Abaham menggunakan 400 Syikal perak sebagai alat pembayaran (Kej. 23: 1-20). ${ }^{19}$ Perak tersebut belum berbentuk lempengan atau plat, melainkan berbentuk potongan atau bongkahan logam perak biasa. ${ }^{20}$ Menurut Perry Stone penemuan arkeologi menjadi bukti otentik terhadap kesimpulan ini. ${ }^{21}$

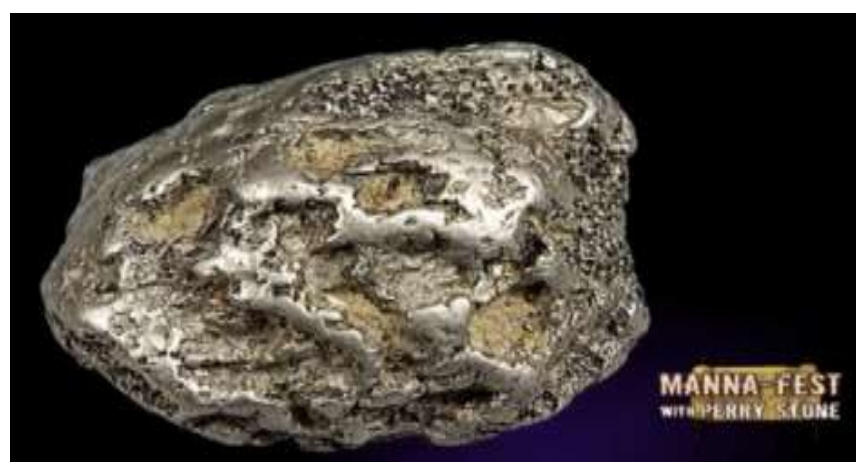

Gambar 2. Ilustrasi uang dari bongkahan perak. $^{22}$

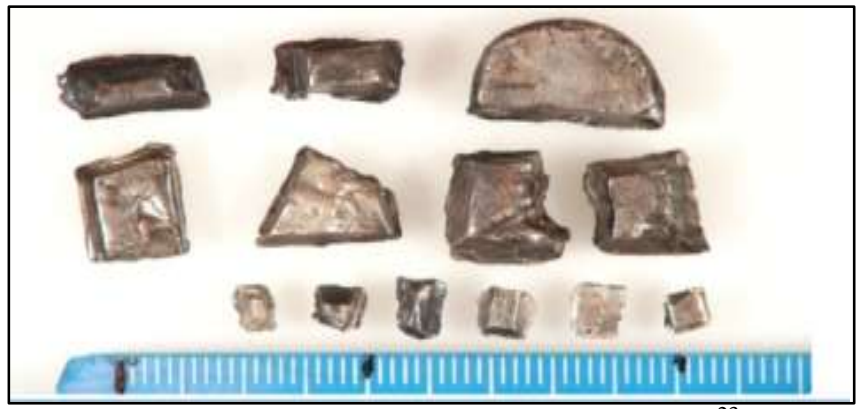

Gambar 3. Ilustrasi mata uang perak kuno. ${ }^{23}$

Penggalian arkeologi di Israel memberikan konfirmasi dominasi perak dalam ekonomi Levantine (Mediterania) kuno. Sumber teks kuno lainnya seperti

18 Stone, A Study on Ancient Bible Currency.

19 David Govmint.com \& Levine, Coins of the Bible 1: When was money first mentioned in the Bible? (Govmint.com Coin, 2014).

20 Govmint.com \& Levine.

${ }^{21}$ Stone, A Study on Ancient Bible Currency.

22 Stone.

${ }^{23}$ Eshel, "How Silver Was Used for Payment." 
arsip Ugarit dan dokumen Pajak Paku juga mendukung fakta ini. Semakin banyak "harta karun" perak kuno yang ditemukan melalui penggalian arkeologi, semakin menjelaskan bahwa perak digunakan sebagai mata uang utama dalam Perjanjian Lama. $^{24}$

\section{Konsep Uang Dalam Perjanjian Baru}

Perak tetap menjadi mata uang utama untuk keperluan perdagangan, membayar pajak, ataupun persembahan peribadatan di masa Perjanjian Baru.

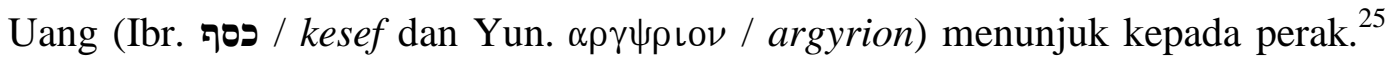
Di masa Perjanjian Baru uang perak digunakan dalam bentuk koin. ${ }^{26}$ Koin sebagai mata uang muncul puluhan kali di dalam Perjanjian Baru. Beberapa berasal dari zaman Helenistik, sementara yang lain berasal dari periode pemerintahan Hasmonean atau Romawi. Setelah Alexander Agung menaklukkan Timur Dekat kuno pada abad ke 4 SM, koin dengan gambar Alexander atau suksesornya beredar di Yudea selama beberapa abad. Koin perak yang disebut "statera" syikal atau koin empat drachma ${ }^{27}$ (Mat. 17: 27) yang ditemukan Petrus dalam mulut ikan (Mat. 17: 24-27) kemungkinan adalah koin Tyrian. Tiga puluh keping uang perak yang diberikan oleh para imam kepala kepada Yudas untuk mengkhianati dan menjual Yesus (Mat. 26: 14-15, 47-50, 27: 3) kemungkinan besar adalah syikal Tyrian, karena koin ini menjadi mata uang yang diterima di Bait Suci di Yerusalem dan para imam pasti memiliki persediaan yang cukup dari koin ini. $^{28}$ Mengenai 30 keping uang perak Yudas, teks Matius 27: 9

24 Eshel.

25 Leon-Dufour, Dictionary of the New Testament, 293-94.

26 Stone, A Study on Ancient Bible Currency.

${ }^{27}$ Rick Harris, Hall \& Holmes, Michael W. \& Brannan, The Lexham English Bible English-Greek Reverse Interlinear New Testament (Bellingham: Logos Bible Sofware, 2010), 95.

28 Longman, Tremper \& Enns, Peter \& Strauss, The Baker Illustrated Bible Dictionary, 737. 
menggunakan kata "argyria",29 atau perak yang berlaku sebagai uang untuk membeli tanah Hakaldama. Yeremia 32: 9 yang merupakan sumber penulisan Matius untuk teks Matius 27: 9-10, menggunakan kata Ibrani "kesef" untuk uang dan perak $^{30}$ untuk membeli tanah. Jadi meskipun kedua teks Matius 27: 9 dan Yeremia 32: 9 dicatat dan terjadi pada waktu dan konteks yang berbeda, namun ada kesamaan diantara keduanya tentang perak yang dipergunakan sebagai uang atau alat pembayaran untuk membeli tanah. ${ }^{31}$

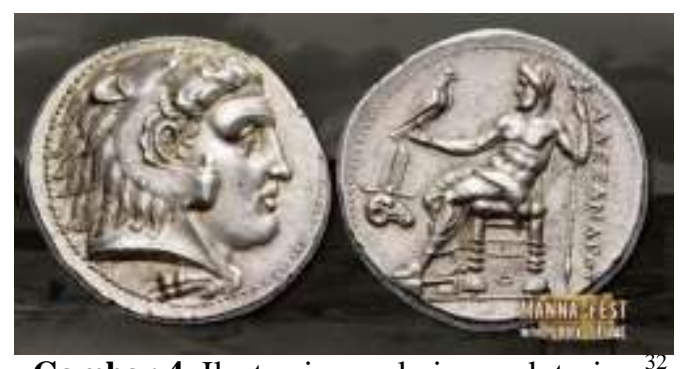

Gambar 4. Ilustrasi uang koin perak tyrian. ${ }^{32}$

Orang Yahudi pada masa Perjanjian Baru memiliki mata uang khusus yang disebut lepton (jamak: lepta) atau prutah dari koin tembaga kecil atau koin perunggu sederhana yang memiliki tulisan di satu sisi dan gambar dua cornucopias dan delima di sisi lain. Simbol pertanian yang digunakan di koin ini untuk memenuhi dua tujuan yaitu menggambarkan kesuburan tanah yang telah diberikan Tuhan kepada umat-Nya ${ }^{33}$ dan membantu orang Yahudi menghindari penggambaran orang atau dewa-dewa berhala di koin, seperti yang dilakukan orang Yunani dan Romawi. ${ }^{34}$ Orang Yahudi menghindari gambar seperti itu untuk taat terhadap perintah kedua dari 10 Hukum (Kel. 20: 4). ${ }^{35}$ Koin-koin ini tetap beredar selama tahun-tahun pelayanan Yesus. Dua uang logam kecil yang

\footnotetext{
${ }^{29}$ Harris, Hall \& Holmes, Michael W. \& Brannan, The Lexham English Bible English-Greek Reverse Interlinear New Testament, 159.

30 James Strong, Strong's Hebrew Dictionary, 2000, 336.

31 Gleason L. Archer, New International Encyclopedia Of Bible Difficulties (Zondervan, 2011), 511.

32 Stone, A Study on Ancient Bible Currency.

33 Longman, Tremper \& Enns, Peter \& Strauss, The Baker Illustrated Bible Dictionary, 738.

34 Stone, A Study on Ancient Bible Currency.

35 Merrill C. Douglas, J. D. \& Tenney, Zondervan Illustrated Bible Dictionary (Zondervan, 2009), 2019.
} 
diberikan janda ke perbendaharaan Bait Suci dan dipuji oleh Yesus dalam Markus 12:42 dan Lukas 21:2 kemungkinan besar menunjuk pada lepta Alexander Jannaeus.

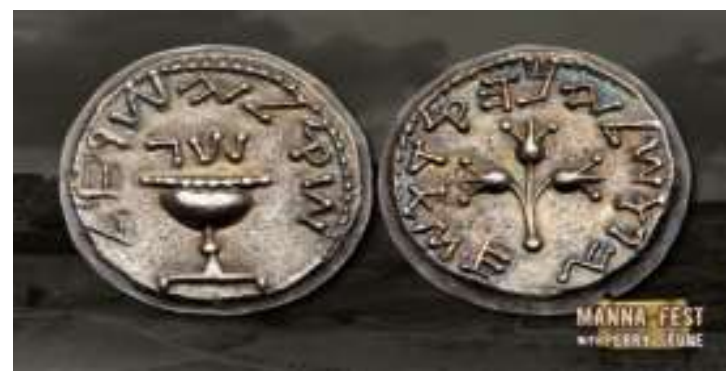

Gambar 5. Ilustrasi uang koin perak Yahudi. ${ }^{36}$

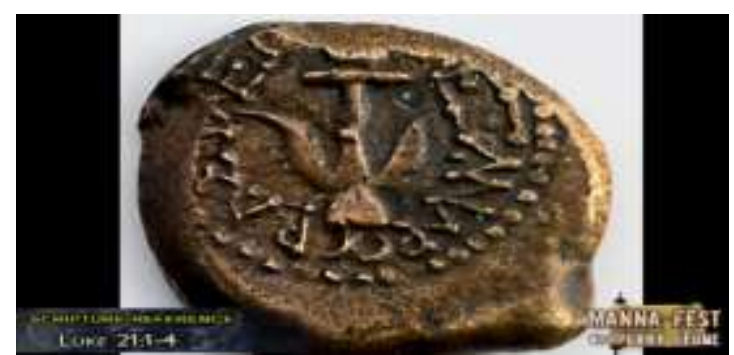

Gambar 6. Ilustrasi uang koin perunggu janda miskin. ${ }^{37}$

Permintaan Yesus untuk koin dengan gambar dan tulisan Kaisar (Mat. 22: 15-22) mengacu pada dinar karena dalam ayat 19 kata asli untuk uang yang ditunjukkan pada Yesus adalah "denarion." 38 Satu dinar merupakan upah harian seorang pekerja biasa, seperti yang disebutkan dalam perumpamaan tentang pekerja di kebun anggur (Mat. 20: 1-16). Dinar muncul di banyak bagian lain, namun penerjemah modern kadang-kadang menggunakan ekspresi yang lebih interpretatif yaitu "dua koin perak" untuk "dua dinar" (Luk. 10: 35) dan "upah setahun" untuk "tiga ratus dinar" (Mrk. 14: 5). ${ }^{39}$

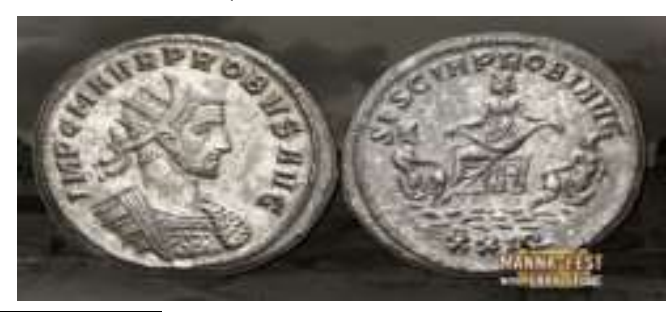

36 Stone, A Study on Ancient Bible Currency.

37 Stone.

38 Harris, Hall \& Holmes, Michael W. \& Brannan, The Lexham English Bible English-Greek Reverse Interlinear New Testament, 122.

39 Longman, Tremper \& Enns, Peter \& Strauss, The Baker Illustrated Bible Dictionary, 739-40. 
Gambar 7. Ilustrasi uang koin perak dinar. ${ }^{40}$

Istilah umum yaitu "koin" atau "keping uang" terkadang muncul, seperti ketika Yesus menyerakan koin para penukar uang (Yoh. 2: 15). Istilah yang lebih umum untuk perak yang sering muncul diterjemahkan sebagai "uang" (Mat. 28: 12, Luk. 9: 3) atau "perak" (Kis. 3: 6, 1Ptr. 1: 18) serta "koin perak" (Mat. 27: 3). ${ }^{41}$ Dari semua referensi sumber teks-teks Alkitab dapat disimpulkan bahwa mata uang utama di masa Perjanjian Baru berbentuk perak atau koin perak. Hal ini dapat ditelusuri lebih jauh ke masa Perjanjian Lama dan bukti-bukti peninggalan sejarah yang ada hingga hari ini yang ditemukan melalui penggalian arkeologi memberikan validasi atas kesimpulan tersebut. ${ }^{42}$

\section{Dasar Teori Kebebasan Finansial}

Keuangan atau finansial berasal dari kata finance yang berarti pengaturan atau managemen keuangan, ekonomi dan investasi keuangan, ${ }^{43}$ atau segala hal yang berhubungan langsung dengan uang, perekonomian, dan transaksi perbankan secara umum. ${ }^{44}$ Penting untuk memahami pengelolaan keuangan yang sesuai dengan prinsip-prinsip Alkitab serta relevansinya terhadap kehidupan di zaman modern ini. Menurut teori managemen keuangan modern, salah satu tujuan penting untuk memiliki pengelolaan keuangan yang baik adalah agar pengalokasian keuangan untuk kepentingan jangka pendek, menengah ataupun jangka panjang dapat terarah dan terencana dengan baik. ${ }^{45}$ Buruknya pengelolaan keuangan dapat menyebabkan frustrasi dan depresi. Seseorang yang memiliki

\footnotetext{
40 Stone, A Study on Ancient Bible Currency.

${ }^{41}$ Longman, Tremper \& Enns, Peter \& Strauss, The Baker Illustrated Bible Dictionary, 740.

42 Stone, A Study on Ancient Bible Currency.

43 Stuart B. Stein, Jess \& Flexner, Random House Roget's College Thesaurus, Revised (New York: Random House, 2000), 273. 1990), 453.

${ }^{44}$ Clarence Barnhart, The American College Dictionary (New York: Harper \& Brother Publisher, ${ }^{45}$ Keuangan, Perencanaan Keuangan Keluarga, 2017.
} 
pengelolaan keuangan yang baik akan terhindar dari rasa frustrasi maupun depresi ${ }^{46}$ dan dapat dengan bebas menentukan alokasi finansialnya.

Daniel Fridman mendefinisikan kebebasan finansial sebagai persamaan spesifik antara pendapatan dan pengeluaran yang memungkinkan seseorang untuk berhenti dari pekerjaan sambil mempertahankan pendapatan, juga kondisi di mana seseorang telah membebaskan dirinya dari ketakutan dan keterbatasannya sendiri sehubungan dengan uang dan investasi serta kebutuhan akan keamanan. Oleh karena itu, semua praktik yang diarahkan untuk meningkatkan kekayaan seseorang juga merupakan praktik diri yang diarahkan untuk memerangi bentuk ketergantungan eksternal dan internal. Lebih jauh Fridman juga menyimpulkan bahwa uang merupakan sarana utama dalam mencapai kebebasan finansial. ${ }^{47}$ Pengelolaan dan pengendalian keuangan yang baik, ${ }^{48}$ selanjutnya menempatkan uang pada investasi yang tepat dan berkelanjutan ${ }^{49}$ adalah jalan untuk mendapatkan kebebasan finansial (financial freedom).

\section{Prinsip Dasar Kebebasan Finansial Alkitabiah}

Menurut John Piper, Paulus memberikan informasi tentang prinsip dasar kebebasan finansialnya dalam suratnya kepada jemaat di Tesalonika, sehingga Paulus tidak bergantung kepada orang lain untuk memenuhi kebutuhan hidupnya dalam pekerjaan pemberitaan Injil. Prinsip pertama adalah Paulus tidak fokus untuk mencari keuntungan atau mengumpulkan uang. Dalam 1Tesalonika 2: 5 Paulus menyatakan tidak mengejar keuntungan uang dari orang-orang yang

\footnotetext{
${ }^{46}$ Bread, EP. 30: Money Mistakes and How to Cope.

47 Daniel Fridman, "Resisting the lure of the paycheck: Freedom and dependence in financial selfhelp," Foucault Studies, 2014, 90-112, https://doi.org/10.22439/fs.v0i18.4653.

48 Otoritas Jasa Keuangan, Perencanaan Keuangan Keluarga, Perencanaan Keuangan Keluarga Dan Dampaknya Terhadap Peningkatan Kesejahteraan Masyarakat, 2017.

${ }^{49}$ Andreas Rudiwantoro, "Langkah penting generasi millennial menuju kebebasan finansial melalui investasi," Moneter - Jurnal Akuntansi dan Keuangan, 2018.
} 
dilayani, maka Paulus dapat berbicara tentang Injil dengan berani dan tegas tanpa beban atau pertimbangan atas perasaan orang-orang kaya yang dilayani. Prinsip kedua dapat ditemukan dalam 1Tesalonika 2: 9, bagaimana Paulus dengan waspada menjaga kemandirian dan kebebasan finansialnya dengan tetap bekerja untuk menghasilkan uang bagi kebutuhan hidupnya. ${ }^{50}$

Ivan Mesa dalam artikelnya yang berjudul How to Honor Your Maker with Your Wallet, menyatakan prinsip penting lain untuk dapat mengalami kebebasan finansial dan kepuasan sejati dalam keuangan. Prinsip tersebut adalah memiliki kemurahan hati sebagaimana teladan yang telah diberikan Allah (Yoh. 3: 16). Berbicara tentang kebebasan finansial dari perspektif Alkitab adalah berbicara tentang kebutuhan akan uang. Setiap orang memang membutuhkan uang tapi setiap orang juga butuh untuk terbebas dari bahaya yang dapat ditimbuhkan oleh uang. ${ }^{51}$ Prinsip-prinsip inilah yang menjadi dasar pengembangan pemikiran tentang kebebasan finansial Alkitab.

\section{Moralitas Dalam Pengelolaan Keuangan Alkitabiah}

Seseorang yang memiliki kebebasan finansial dapat membangun pekerjaan di sekitar keluarga, sebaliknya orang yang tidak memiliki kebebasan finansial membangun keluarga di sekitar pekerjaan. ${ }^{52}$ Kemampuan yang baik dalam pengelolaan keuangan sangat dibutuhkan, agar dapat mengelola keuangan dengan memadai dalam rangka mempersiapkan masa depan yang bebas dan mandiri

\footnotetext{
50 John Piper, "We Had Boldness in Our God," Desiring God, no. May 30, 1993 (1993).

51 Ivan Mesa, "How to Honor Your Maker with Your Wallet," The Gospel Coalition, no. January 5, 2017 (2017)

52 Bill Gothard, "Advanced Seminar Textbook," dalam Research in Principles of Life (Illinois, USA: Institute In Basic Youth Conflicts, 1986), 88.
} 
secara finansial. ${ }^{53}$ Seseorang yang tidak memiliki pengendalian yang baik terhadap keuangan, biasanya juga tidak memiliki pengendalian yang baik secara moral. ${ }^{54}$ Amsal 6: 26 dan 29: 3 menyatakan bahwa uang hanyalah instrumen, yang terpenting adalah moral dan sikap hati orang yang memiliki uang tersebut. Mengenai ayat di atas, The Oxford Bible Commentary menginterpretasikan bahwa perempuan sundal hanya perduli tentang bayaran mahal yang diperolehnya, sehingga seseorang akan jatuh miskin jika melakukan percabulan dengan perempuan sundal, sehingga secara garis besar Amsal 6: 20-35 menasehatkan agar menghindari pelacuran. ${ }^{55}$ Untuk menghindari pelacuran dan pemborosan harta orang percaya perlu selalu mengingat bahawa pada hakikatnya segala sesuatu kepunyaan Tuhan (Bdk. Mzm. 127: 3-5). Takut akan Tuhan, sikap hati dan moral yang benar merupakan kunci utama pengendalian diri dalam pengelolaan keuangan.

\section{Hutang Piutang Dalam Sistem Pengelolaan Keuangan Alkitabiah}

Sistem perbankan (finansial) tidak dapat dilepaskan dari kegiatan dasarnya, salah satu memberikan kredit atau hutang. Alkitab sendiri menjelaskan dan mengomentari praktik semacam itu di Perjanjian Lama maupun Perjanjian Baru. $^{56}$ Pandangan tentang hutang harus berakar dari pandangan Alkitab. ${ }^{57}$ Kebenaran Alkitab harus mengoreksi asumsi umum tentang hutang dan pengeluaran. Jika tidak, akan sulit mendapatkan dasar yang teguh dalam cara memahami uang, menghindari hutang dan menggunakan uang untuk memuliakan

${ }^{53}$ Andreas Rudiwantoro, "Langkah penting generasi millennial menuju kebebasan finansial melalui investasi," Moneter - Jurnal Akuntansi dan Keuangan, 2018.

54 Gothard, "Advanced Seminar Textbook," 88.

55 John Barton, John \& Muddiman, The Oxford Bible Commentary (New York, USA: Oxford University Press, 2001), 436.

56 Longman, Tremper \& Enns, Peter \& Strauss, The Baker Illustrated Bible Dictionary, 384.

57 Paul Tripp, "Debt Is Not a Money Problem," Desiring God, 2018. 
Tuhan. ${ }^{58}$ Peringatan yang tertulis dalam Amsal 22: 7 menjadi peringatan penting bagi peminjam (debitur) dan juga pemberi pinjaman (kreditur) agar tidak memanfaatkan orang miskin. Konteks Amsal 22 sejalan dengan seluruh keadilan ekonomi Alkitabiah ${ }^{59}$ karena dampak dari hutang menciptakan sistem kapitalisme, dimana orang kaya menguasai dan menindas orang miskin dan sebaliknya orang miskin akan terikat karena hutang. ${ }^{60}$ Oleh karena itu, sejak masa Israel kuno sistem hutang piutang ini telah diatur, di mana dalam sistem pinjam-meminjam diantara sesama orang Israel tidak diperkenankan adanya beban bunga (interest) untuk menghindari eksploitasi orang yang berhutang, khususnya orang miskin.

Hukum Israel mengatur praktik pemberian pinjaman terutama untuk melindungi orang miskin dari eksploitasi. Tidak diizinkan membebankan bunga pinjaman kepada sesama orang Israel, dan juga ditetapkan aturan mengenai pengambilan, kepemilikan, dan pengembalian agunan (Kel. 22: 25; Ul. 23: 19, 24 : 6,10-13,17; Neh. 5: 1-13; Yeh. 33: 15). Setiap tujuh tahun orang yang memberikan pinjaman diminta untuk membebaskan orang yang meminjam dari hutangnya (Ul. 15: 1-3). Namun, aturan ini tidak berlaku jika peminjamnya adalah orang asing. Pada zaman Perjanjian Baru, aktivitas perbankan kemudian lebih berkembang dan diinformalkan. Penyetoran uang untuk bunga telah diberlakukan (Mat. 25: 27; Luk. 19: 23). Koin yang dicetak secara lokal dan beragam, digunakan secara luas di Kekaisaran Romawi. Koin dinar digunakan oleh Romawi dan koin drachma digunakan oleh Yunani (Luk. 20: 24; Mat. 17: 24). Layananan penukaran uang sudah lazim terjadi, dimana para penukar uang

\footnotetext{
58 Tripp.

59 Eric Howell, "Payday lending and the case of Proverbs 22:7: Wisdom for the borrower and warning to the lender," Review \& Expositor 116, no. 1 (2019), https://doi.org/10.1177/0034637319831234.

60 David Noebel, Understanding The Times: The Religious Worldviews of Our Day and The Search for Truth (Oregon, USA: Harvest House Publishers, 1991), 448-54.
} 
biasanya memasang meja khusus yang diberi tanda di sekitar Bait Suci dan bangunan umum. Kata Yunani Perjanjian Baru untuk "bankir," adalah trapezitēs, berasal dari kata trapeza artinya "table" atau meja. Istilah bankir sangat identik dengan meja, hal tersebut dapat dilihat pada praktik para penukar uang dengan meja khususnya di Bait Suci Yerusalem yang telah membuat Yesus marah dan membalikkan meja para bankir (Mat. 21: 12; Mrk. 11: 15; Yoh. 2: 15). ${ }^{61}$

Di zaman Israel kuno, jika seseorang pailit dapat secara hukum menyatakan ketidakmampuan untuk membayar hutang, tetapi Tuhan juga menetapkan jenis prosedur kebangkrutan bagi debitur termiskin Israel. Meskipun pailit, Tuhan memerintahkan agar kewajiban hutang tetap harus dibayar kembali. Untuk membayar kewajiban, debitur yang pailit dapat memberikan enam tahun kehidupannya sebagai budak dan kreditor harus membebaskan hambanya itu setiap tahun ketujuh (Kel. 21: 2). Selain itu, pembebasan pada tahun Yobel (Im. 25: 10) juga memberikan perlindungan kepada orang miskin terhadap persyaratan yang menindas dan mengeksploitasi (Neh. 5: 3-5). ${ }^{62}$

Praktik hutang piutang tidak dilarang secara eksplisit, namun harus dilakukan dengan ketetapan dan konsekuensi yang tertulis di Hukum Taurat. Tapi meskipun tidak dilarang, seseorang tidak akan pernah mendapatkan kebebasan finansial jika terikat dengan hutang piutang. Oleh karenanya, tidak berlebihan untuk mengatakan bahwa menurut pandangan Alkitab, memiliki beban hutang tidak sesuai dengan maksud Tuhan. ${ }^{63}$ Lebih baik bebas dari hutang karena firman Tuhan memberikan jaminan bahwa Allah memenuhi segala keperluan (Flp. 4: 19).

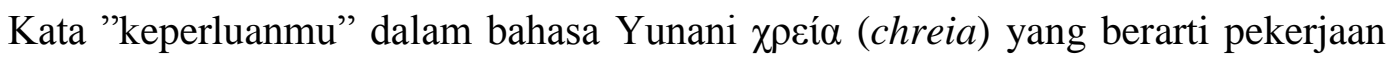

\footnotetext{
61 Longman, Tremper \& Enns, Peter \& Strauss, The Baker Illustrated Bible Dictionary, 386.

62 Longman, Tremper \& Enns, Peter \& Strauss, 386-87.

63 Gothard, "Advanced Seminar Textbook," 88.
} 
(employment) ${ }^{64}$ atau kebutuhan (necessity), yang implikasinya berarti kebutuhan jasmani. ${ }^{65}$ Bible Knowledge Commentary menginterpretasi konteks teks ini berhubungan dengan uang. Paulus memberikan pujian bagi jemaat Filipi karena telah mengirimkan bantuan keuangan untuk kebutuhan Paulus dan pelayanannya. Kemudian di bagian akhir, Paulus berdoa agar Tuhan memenuhi segala kebutuhan jemaat Filipi melalui berkat keuangan. ${ }^{66}$

Hutang pada dasarnya adalah masalah kepuasan 1Timotius 6: 6-10 memberikan petunjuk bahwa cinta uang berhubungan dengan hal-hal yang jauh lebih besar dari pada uang. Paulus memulai pembahasannya dengan 'kepuasan' karena akar masalah dengan uang. Hanya ketika rahmat Tuhan telah terbentuk dalam diri seseorang dengan hati yang benar-benar puas, baru seseorang dapat menjalani kehidupan yang terkendali secara finansial, tidak mengikuti jejak dari setiap keinginan egois yang dapat menguras keuangan. Ketika hati berkomitmen dan dipuaskan oleh kemuliaan Tuhan, hati akan puas, dan dengan demikian akan terbebas dari tirani yang menyebabkan hutang. Menghabiskan uang untuk mengejar kebahagiaan pribadi tidak pernah menghasilkan kebahagiaan yang sesungguhnya, sebaliknya itu hanya menghasilkan hutang dengan semua tekanan emosional dan spiritual yang menyertainya. ${ }^{67}$ Prinsip penting dari Salomo dalam permohonan kepada Tuhan memilih untuk meminta hikmat dari pada uang (1Raj. 3: 12-13). ${ }^{68}$ Karena Salomo meminta hikmat maka Tuhan memberikan hikmat (Ams. 2: 6), tetapi tidak hanya itu Tuhan juga memberikan jaminan atas segala 64 Ted Hildebrandt, Mastering New Testament Greek Greek-English Lexicon (Grand Rapids, USA: Baker Academic, 2003), 63.

65 W. E. Vine, VINE'S Expository Dictionary of Old and New Testament Words (Old Tappan, New Jersey: Fleming H. Revell Company, 1981), 105.

66 Roy B. Walvoord, John F. \& Zuck, The Bible Knowledge Commentary: New Testament (Eastbourne, England: David Cook, 1983), 665.

67 Tripp, "Debt Is Not a Money Problem."

68 Gothard, "Advanced Seminar Textbook," 88. 
sesuatu yang tidak Salomo minta, ${ }^{69}$ termasuk uang dan kekayaan. Dengan demikian dapat ditarik kesimpulan bahwa memiliki hikmat dan mengasihi Tuhan melebihi uang adalah kunci utama untuk dapat mengelola keuangan dengan baik, salah satunya adalah dengan menghindari hutang agar dapat memiliki kemandirian atau kebebasan dalam pengelolaan finansial.

\section{Tujuan Uang Dan Pengelolaannya Dari Prespektif Alkitabiah}

Hal terpenting ketika membicarakan keuangan adalah apa yang Tuhan pikirkan dan firmankan tentang uang. Mazmur 50:12 menyatakan bahwa segala sesuatu di dunia ini adalah kepunyaan Tuhan, termasuk uang dan kekayaan yang dimiliki setiap orang. ${ }^{70}$ Dunia tidak diciptakan untuk menjadi sarana pribadi manusia mewujudkan kebahagiaan menurut definisinya sendiri. Demikian juga uang, uang tidak diciptakan hanya untuk membawa semua hal yang diinginkan seseorang ke dalam hidupnya. Jika tidak memulai dengan penyerahan dan ketaatan pada Tuhan, walaupun seseorang tidak memiliki hutang, pengelolaan keuangan yang dilakukanya tidak akan pernah sesuai dengan cara dan tujuan yang Tuhan maksudkan. ${ }^{71}$ Oleh karena itu, penting untuk mengetahui kebenaran firman Tuhan yang berhubungan dengan prinsip mengelola keuangan.

Ketaatan terhadap firman Tuhan akan membawa berkat Tuhan (Lih. Ams. 3: 9-10). Pada prinsipnya manusia hanya diberikan kuasa oleh Tuhan sebagai pengelola dan pengatur keuangan yang Tuhan percayakan untuk kemuliaan Tuhan, bukan sebagai pemilik karena Tuhan sendirilah pemiliknya. ${ }^{72}$ Implikasi prinsip ini adalah kelimpahan materi dari hasil pekerjaan maupun keuntungan dari

69 Barton, John \& Muddiman, The Oxford Bible Commentary, 236.

70 Ministries, God and Our Money - Dr. Charles Stanley.

71 Tripp, "Debt Is Not a Money Problem."

72 Ministries, God and Our Money - Dr. Charles Stanley. 
investasi dalam pengelolaan keuangan harus diberikan dan dipertanggungjawabkan kepada Tuhan. Menurut MacArthur, penting untuk memahami pengelolaan keuangan karena banyak orang tidak memberikan apa yang seharusnya mereka berikan kepada Tuhan. Utamanya adalah persepuluhan. Selain karena tidak mencintai Tuhan sebagaimana mestinya, menggunakan uang hanya untuk diri sendiri, tidak mengerti apa yang harus diberikan, persoalan keuangan karena terlilit hutang piutang merupakan faktor utama orang Kristen tidak memberi persepuluhan. Karenanya, hutang piutang perlu disikapi dengan bijak.$^{73}$ Dikatakan sebelumnya bahwa lebih baik untuk tidak berhutang, namun sistem sosial ekonomi dalam kehidupan di zaman modern ini tidak dapat dilepaskan dari sistem kredit atau hutang piutang. Hampir setiap orang terlibat di dalam sistem ini untuk memenuhi kebutuhan dasar seperti membeli rumah atau kendaraan dengan sistem kredit. Oleh karena itu, perlu dikemukakan suatu konsep praktis pola pengaturan keuangan yang sesuai dengan prinsip-prinsip Alkitabiah namun relevan dengan sistem sosial ekonomi kehidupan modern saat ini. Sebagai alternatif, berikut ini pola yang dapat digunakan oleh setiap orang Kristen untuk mengelola keuangan dengan baik.

Pola pengelolaan keuangan ini disebut 10-70-20 yang dikemukakan oleh George M. Bowman dan George Fooshee, sebagaimana dikutip oleh Ed Young di dalam bukunya yang berjudul The 10 Commandments of Marriage. Konsep awal adalah menyisihkan persepuluhan (10\%) dan pajak penghasilan dari penghasilan bruto bulanan. Firman Tuhan memerintahakan untuk membawa "hasil pertama" maka persepuluhan harus dihitung dari penghasilan bruto bukan neto. Setelah itu

73 John MacArthur, "The Biblical View of Money, Part 1," dalam Grace To You, 1995. 
lakukan pemotongan pajak untuk dibayarkan bagi negara (Mat. 22: 21). ${ }^{74}$ Setelah menyisihkan kedua item persepuluhan dan pajak, maka kemudian diperoleh $100 \%$ penghasilan neto bulanan. Dari penghasilan neto, pertama, sisihkan $10 \%$ untuk ditabung atau diinvestasikan, dapat juga dijadikan dana cadangan untuk keadaan darurat. Kedua, sisihkan $70 \%$ untuk biaya kebutuhan hidup sehari-hari. Cukupkan diri atas berbagai kebutuhan dengan $70 \%$ anggaran dengan hikmat dan sikap hati yang penuh syukur. Ketiga, gunakan $20 \%$ sisa anggaran yang ada untuk pembayaran hutang seperti cicilan rumah atau cicilan kendaraan. Berdasarkan pola ini, beban hutang yang harus dibayar setiap bulan tidak boleh lebih dari $20 \%$ penghasilan neto bulanan. ${ }^{75}$

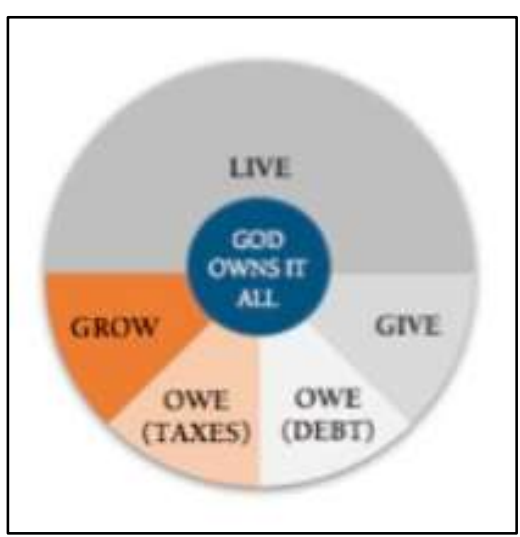

Gambar 8. Diagram Tuhan pemiliki segala sesuatu. ${ }^{76}$

Model Alkitabiah memberikan gagasan bahwa keuangan adalah bagian dari struktur yang dimaksudkan Tuhan untuk dunia. Keuangan maupun sistem pengelolaannya harus berkontribusi bagi promosi "shalom," yang memberikan kemajuan dan perkembangan secara universal baik bagi umat manusia maupun bumi. ${ }^{77}$ Menurut Wall, orang percaya harus memandang uang dari sudut pandang sebagai murid Yesus bukan sebagai murid uang, karena walaupun uang dapat

74 Ed Young, The 10 Commandments of Marriage (Bandung: Lembaga Literatur Baptis, 2003), 130.

75 Young, 130.

76 Mesa, "How to Honor Your Maker with Your Wallet."

77 Todd P. Steen, Steve VanderVeen, dan Julie Voskuil, "Finance: on earth as it is in heaven?," Managerial Finance 32, no. 10 (2006), https://doi.org/10.1108/03074350710688297. 
menjadi sarana untuk kebahagiaan, tapi uang juga dapat menjadi sarana untuk kejahatan. ${ }^{78}$ Oleh sebab itu, seseorang harus melepaskan diri dari perbudakan cinta uang yang mencuri sukacita, dan masuk ke dalam kebebasan yang Tuhan Yesus tawarkan, dimana uang menjadi hamba dari sukacita di dalam Tuhan.

Ketika Yesus masih di bumi, orang Yahudi dan non-Yahudi tidak berhubungan satu sama lain. Tapi setelah Yesus kembali ke Surga dan Kekristenan berkembang, Tuhan menyelesaikan masalah perbedaan ini dengan cara mutualisme atau saling menguntungkan dengan cara Injil diberitakan oleh orang Yahudi kepada orang non Yahudi, kemudian sebaliknya orang non Yahudi memberikan bantuan finansial kepada orang Yahudi yang mengalami kelaparan dan penderitaan di Yerusalem. Prinsip ini menjadi gambaran yang jelas tentang tujuan Tuhan terhadap uang (2Kor. 8: 14). Tuhan selalu memberikan petunjuk yang tepat pada saat kekurangan uang, sebagaimana juga pada saat memiliki uang. Oleh karenanya, dalam mengambil keputusan finansial dibutuhkan komitmen untuk melihat petunjuk dan waktu Tuhan (2Taw. 16: 9). ${ }^{79}$

Memiliki hidup yang sederhana akan menolong seseorang untuk menggunakan uangnya sesuai tujuan Tuhan yaitu untuk membantu memenuhi kebutuhan orang lain. Ini berarti memaksimalkan harta dan sukacita di surga, bukan di bumi. Hati akan bergerak menuju apa yang dihargai, dan Tuhan ingin hati setiap orang percaya bergerak ke arah-Nya. ${ }^{80}$ Hidup dengan sederhana, mencukupkan diri sesuai dengan penghasilan yang diperoleh dan menggunakan uang sesuai tujuan Tuhan merupakan wujud kebebasan finansial Alkitabiah yang sejati.

\footnotetext{
${ }^{78}$ Waldean Wall, "Make Money Serve Your Joy," Desiring God, 2017.

79 Gothard, "Advanced Seminar Textbook," 89.

80 John Piper, "Magnifying God with Money," Desiring God, 1997.
} 


\section{Implikasi Praktis Pengelolaan Keuangan Alkitabiah}

Setiap orang Kristen pada hakekatnya adalah hamba Tuhan, namun setiap orang Kristen juga dapat dengan mudah menjadi hamba uang jika tidak memiliki dasar dan pandangan yang kokoh sesuai ajaran Alkitab tentang finansial. Dibutuhkan penyerahan diri dan pengorbanan untuk dapat mempertanggungjawabkan uang yang Tuhan percayakan bagi kemuliaan-Nya. ${ }^{81}$ Mempersembahkan uang kepada Tuhan merupakan suatu langkah yang serius. Orang percaya hendaknya jangan fokus mencari kesenangan sejati dalam uang, Tuhan adalah satu-satunya harta yang tidak pernah gagal (Luk. 12: 33), satusatunya sukacita yang luar biasa (Mzm. 43: 4). Jika uang menjadi berhala, persembahkan uang tersebut kepada Tuhan. ${ }^{82}$ Pada momen persembahan itu dilakukan, maka Tuhanlah yang sepenuhnya berhak dan berotoritas atas persembahan itu, dan bukan lagi orang yang mempersembahkannya. Orang yang memberikan persembahan senantiasa bersukur pada Tuhan atas apapun yang terjadi pada persembahannya tersebut. ${ }^{83}$

Jangan melayani uang agar uang tidak mengontrol hidup dan menghilangkan sukacita. Sebaliknya, jadikan uang sarana pelayanan dan sukacita di dalam Tuhan (Mat. 13: 44). ${ }^{84}$ Tujuan utama mempersembahkan uang kepada Tuhan adalah agar Tuhan memakai hal itu untuk kemuliaan-Nya dan orang yang memberi persembahan tersebut semakin memperolah Kristus. ${ }^{85}$ Persembahan persepuluhan adalah bukti keterkaitan erat antara uang dengan ibadah.

81 Harold Fickett, Kepercayaan Kaum Baptis: Suatu Pedoman (Bandung: Lembaga Literatur Baptis, 2011), 109-11.

82 Wall, "Make Money Serve Your Joy."

${ }^{83}$ Gothard, "Advanced Seminar Textbook," 94.

84 Wall, "Make Money Serve Your Joy."

85 Gothard, "Advanced Seminar Textbook," 94. 
Persepuluhan adalah prinsip untuk memberi dengan sukacita, teratur, sistematis, proporsional dan bebas untuk pekerjaan Tuhan. Ini adalah disiplin rohani yang penting untuk mengingatkan bahwa Tuhanlah yang memberi dan pemilik segala sesuatu, termasuk semua uang yang ada. ${ }^{86}$

Stanley menjelaskan prinsip-prinsip utama memberi persepuluhan dari penghasilan kepada Tuhan berdasarkan Maleakhi 3: 8-12. Prinsip pertama adalah memberi untuk pekerjaan Tuhan. Memberi agar Injil diberitakan semakin luas. ${ }^{87}$ Mengenai hal ini Fickett juga mengemukakan bahwa setiap orang Kristen mempunyai tanggungjawab keuangan bagi pekerjaan Tuhan Yesus Kristus dalam Gereja-Nya. ${ }^{88}$ Prinsip kedua adalah memberi untuk penghargaan berkat Tuhan. Artinya persepuluhan adalah wujud penghargaan atas berkat Tuhan. ${ }^{89}$ Allah Mahakuasa membuat manusia menjadi pengurus atas segala milik-Nya dan manusia bertanggungjawab kepada Allah atas segala yang dipercayakan Allah padanya. ${ }^{90}$ Prinsip ketiga adalah memberi untuk membuktikan kesetiaan Tuhan. Tuhan meminta ketaatan untuk memberi persepuluhan agar Tuhan dapat membuktikan bahwa diriNya adalah pemilik segala sesuatu dan meskipun uang diperolah melalui bekerja tapi sebenarnya Tuhan yang memberikanya. ${ }^{91}$ Berdasarkan hal itu, setiap orang bertanggungjawab kepada Allah mengenai yang mereka lakukan atas uang mereka sendiri. ${ }^{92}$ Suatu kewajiban untuk memberi dengan sukacita sebagai bentuk pengorbanan bagi Tuhan, sebagaimana Tuhan

\footnotetext{
${ }^{86}$ SBTS Faculty, An Exposition from the Faculty of The Southern Baptist Theological Seminary on The Baptist Faith and Message 2000 (Louisville, KY 40280: SBTS Press, 2001), 36.

${ }^{87}$ Ministries, God and Our Money - Dr. Charles Stanley.

88 Fickett, Kepercayaan Kaum Baptis: Suatu Pedoman, 110.

89 SBTS Faculty, An Exposition from the Faculty of The Southern Baptist Theological Seminary on The Baptist Faith and Message 2000, 36.

${ }^{90}$ Fickett, Kepercayaan Kaum Baptis: Suatu Pedoman, 111.

91 Ministries, God and Our Money - Dr. Charles Stanley.

92 Fickett, Kepercayaan Kaum Baptis: Suatu Pedoman, 111.
} 
telah memberkati dan menjanjikan berkat yang akan diberikan kemudian. ${ }^{93}$ Uang adalah area dimana setiap orang harus bertanggungjawab. Oleh sebab itu, memberi kepada Tuhan bukan sekedar penghargaan tapi juga bentuk ketaatan atas iman kepada Tuhan (Lih. Ibr. 11: 6; Yoh. 14: 6; ). ${ }^{94}$ Dengan demikian percaya dan menerima Yesus sebagai Tuhan dan Juruselamat adalah jalan dan bukti seseorang memiliki kebebasan finansial yang sejati.

\section{KESIMPULAN}

Kebebasan finansial Alkitabiah merupakan suatu konstruksi teologis terhadap pengelolaan keuangan berdasarkan prinsip-prinsip Alkitabiah. Pada prinsipnya, uang bukanlah sesuatu yang jahat tapi sikap cinta akan uang lah yang berdampak negatif terhadap kehidupan seseorang. Hal inilah yang juga menyebabkan uang cenderung dipandang dan dikonotasikan negatif. Uang merupakan topik yang penting dalam keseluruhan Alkitab. Tuhan menciptakan segala sesuatu termasuk uang untuk tujuan yang baik bagi kemuliaan-Nya. Oleh karena itu, tidak menjadi masalah berapa pun banyaknya uang yang Tuhan percayakan untuk dimiliki seseorang, namun yang terpenting adalah dalam pengelolaanya harus dilakukan berdasarkan prinsip-prinsip kebenaran firman Tuhan. Seseorang yang memiliki kebebasan finansial secara Alkitabiah adalah orang yang menghasilkan uang dengan cara yang benar dan mampu mengelolanya dengan mandiri dan benar berdasarkan prinsip-prinsip firman Tuhan tanpa bergantung pada pihak lain. Untuk dapat melakukanya seseorang harus beriman dan percaya kepada Tuhan Yesus Kristus dan mengasihi Tuhan lebih dari

${ }^{93}$ SBTS Faculty, An Exposition from the Faculty of The Southern Baptist Theological Seminary on The Baptist Faith and Message 2000, 36.

94 Ministries, God and Our Money - Dr. Charles Stanley. 
segalanya. Hanya dengan demikian, seseorang dapat mempersembahkan seluruh uang dan kekayaannya bagi kemuliaan Tuhan. Memiliki hati dan moral yang benar dapat mengelola keuangan secara benar dan proporsional sesuai dengan tanggungjawab dan kebutuhan, mampu menahan diri untuk tidak terjerumus ke dalam ikatan hutang piutang, memiliki kemurahan hati dengan menggunakan sumber daya finansial untuk memberi dan membantu orang lain yang membutuhkan, taat dan setia dalam pengabdian kepada Tuhan dengan rutin memberi persembahan dan persepuluhan bagi pekerjaan pelayanan Tuhan di Gereja.

\section{DAFTAR PUSTAKA}

Archer, Gleason L. New International Encyclopedia Of Bible Difficulties. Zondervan, 2011.

Barnhart, Clarence. The American College Dictionary. New York: Harper \& Brother Publisher, 1990.

Barnhart, Robert K. Dictionary of Etymology. New York: Wilson Company, 1995.

Barton, John \& Muddiman, John. The Oxford Bible Commentary. New York, USA: Oxford University Press, 2001.

Bread, Our Daily. EP. 30: Money Mistakes and How to Cope, 2021.

Douglas, J. D. \& Tenney, Merrill C. Zondervan Illustrated Bible Dictionary. Zondervan, 2009.

Eshel, Tzilla. "How Silver Was Used for Payment.” thetorah.com, 2018.

Fajri, Em Zul \& Senja, Ratu Aprilia. Kamus Lengkap Bahasa Indonesia. Difa Publisher, 2010.

Fickett, Harold. Kepercayaan Kaum Baptis: Suatu Pedoman. Bandung: Lembaga Literatur Baptis, 2011. 
Fridman, Daniel. "Resisting the lure of the paycheck: Freedom and dependence in financial self-help." $\quad$ Foucault 2014. https://doi.org/10.22439/fs.v0i18.4653.

Gothard, Bill. "Advanced Seminar Textbook." Dalam Research in Principles of Life. Illinois, USA: Institute In Basic Youth Conflicts, 1986.

Govmint.com \& Levine, David. Coins of the Bible 1: When was money first mentioned in the Bible? Govmint.com Coin, 2014.

Harris, Hall \& Holmes, Michael W. \& Brannan, Rick. The Lexham English Bible English-Greek Reverse Interlinear New Testament. Bellingham: Logos Bible Sofware, 2010.

Hildebrandt, Ted. Mastering New Testament Greek Greek-English Lexicon. Grand Rapids, USA: Baker Academic, 2003.

Howell, Eric. "Payday lending and the case of Proverbs 22:7: Wisdom for the borrower and warning to the lender." Review \& Expositor 116, no. 1 (2019). https://doi.org/10.1177/0034637319831234.

Keuangan, Otoritas Jasa. Perencanaan Keuangan Keluarga. Perencanaan Keuangan Keluarga Dan Dampaknya Terhadap Peningkatan Kesejahteraan Masyarakat, 2017.

- Perencanaan Keuangan Keluarga. Perencanaan Keuangan Keluarga Dan Dampaknya Terhadap Peningkatan Kesejahteraan Masyarakat, 2017.

Leon-Dufour, Xavier. Dictionary of the New Testament. New York: Harper and Row Publishers, 1983.

Longman, Tremper \& Enns, Peter \& Strauss, Mark. The Baker Illustrated Bible Dictionary. Grand Rapids Michigan, USA: Baker Publishing, 2013.

MacArthur, John. "Overcoming Financial Worry, Part 1." Dalam Grace To You, 2021.

__. "The Biblical View of Money, Part 1.” Dalam Grace To You, 1995.

Mesa, Ivan. "How to Honor Your Maker with Your Wallet." The Gospel Coalition, no. January 5, 2017 (2017).

Ministries, In Touch. God and Our Money - Dr. Charles Stanley, 2019.

Noebel, David. Understanding The Times: The Religious Worldviews of Our Day and The Search for Truth. Oregon, USA: Harvest House Publishers, 1991.

Piper, John. "Magnifying God with Money.” Desiring God, 1997. 
. "We Had Boldness in Our God." Desiring God, no. May 30, 1993 (1993).

Rudiwantoro, Andreas. "Langkah penting generasi millennial menuju kebebasan finansial melalui investasi." Moneter - Jurnal Akuntansi dan Keuangan, 2018.

- "Langkah penting generasi millennial menuju kebebasan finansial melalui investasi.” Moneter - Jurnal Akuntansi dan Keuangan, 2018.

SBTS Faculty. An Exposition from the Faculty of The Southern Baptist Theological Seminary on The Baptist Faith and Message 2000. Louisville, KY 40280: SBTS Press, 2001.

Steen, Todd P., Steve VanderVeen, dan Julie Voskuil. "Finance: on earth as it is in heaven?" Managerial Finance 32, no. $10 \quad$ (2006). https://doi.org/10.1108/03074350710688297.

Stein, Jess \& Flexner, Stuart B. Random House Roget's College Thesaurus. Revised. New York: Random House, 2000.

Stone, Perry. A Study on Ancient Bible Currency. Perry Stone Ministry, 2018.

Strong, James. A Consise Dictionary Of The Words In The Hebrew Bible, 1890.

—. Strong's Hebrew Dictionary, 2000.

Tripp, Paul. “Debt Is Not a Money Problem.” Desiring God, 2018.

W. E. Vine. VINE'S Expository Dictionary of Old and New Testament Words. Old Tappan, New Jersey: Fleming H. Revell Company, 1981.

Wall, Waldean. "Make Money Serve Your Joy.” Desiring God, 2017.

Walvoord, John F. \& Zuck, Roy B. The Bible Knowledge Commentary: New Testament. Eastbourne, England: David Cook, 1983.

Young, Ed. The 10 Commandments of Marriage. Bandung: Lembaga Literatur Baptis, 2003.

Zaluchu, Sonny Eli. "Metode Penelitian di dalam Manuskrip Jurnal Ilmiah Keagamaan." Jurnal Teologi Berita Hidup 3, no. 2 (2021). https://doi.org/10.38189/jtbh.v3i2.93.

. "Strategi Penelitian Kualitatif dan Kuantitatif Di Dalam Penelitian Agama." Evangelikal: Jurnal Teologi Injili dan Pembinaan Warga Jemaat 4, no. 1 (2020): 28-38. https://doi.org/10.46445/ejti.v4i1.167. 